\title{
Preformulation Studies of Econazole: A Vital Part of Formulation Design
}

Khushi Chouksey ${ }^{*}$, Kuldeep Ganju \& Ganesh Prasad Patel

Sagar Institute of Pharmacy \& Technology, Gandhi Nagar Bhopal (M.P) India

DOI: $10.36347 /$ sajp.2020.v09i09.001

| Received: 31.08 .2020 | Accepted: 07.09.2020 | Published: 09.09.2020

*Corresponding author: Khushi Chouksey

\section{Abstract}

Preformulation study is a part which is initiated formerly the new molecule is seeded. In a broader way, it pact with studies of physical, chemical, analytical, and pharmaceutical properties related to molecule and provides idea about suitable modification in molecule to show a better performance. Preformulation parameters study can be linked to production of effective, safer, stable, and reliable pharmaceutical formulation. Econazole is a topical imidazole antifungal. It is active against Candida albicans, Malassezia furfur, Microsporum species, Trichophyton species, and Epidermophyton floccosum.

Keywords: Preformulation study, Econazole, Solubility \& analytical methods.

Copyright @ 2020: This is an open-access article distributed under the terms of the Creative Commons Attribution license which permits unrestricted use, distribution, and reproduction in any medium for non-commercial use (NonCommercial, or CC-BY-NC) provided the original author and source are credited.

\section{INTRODUCTION}

Preformulation study is the basic tread in the rational development of dosage forms of a drug substance. The study includes an examination of physical and chemical properties of a drug substance alone and with combined with excepient. The general attempt of preformulation testing is to generate information helpful to the formulator in developing stable and bioavailable dosage forms that can be mass produced. Preformulation investigations are designed to deliver all necessary data especially physicochemical, physico-mechanical and bio pharmaceutical properties of drug substances, excipients and packaging materials [1]. These studies should spotlight on those physicochemical properties of the new compound that could affect drug performance and development of an efficient dosage form. A systematic understanding of these properties may eventually provide a rational for formulation design, or sustain the need for molecular modification. The plan of this study was to establish some of the physicochemical properties such as solubility, melting point, pKa, dissolution, assay development, stability in solution etc [2-3].

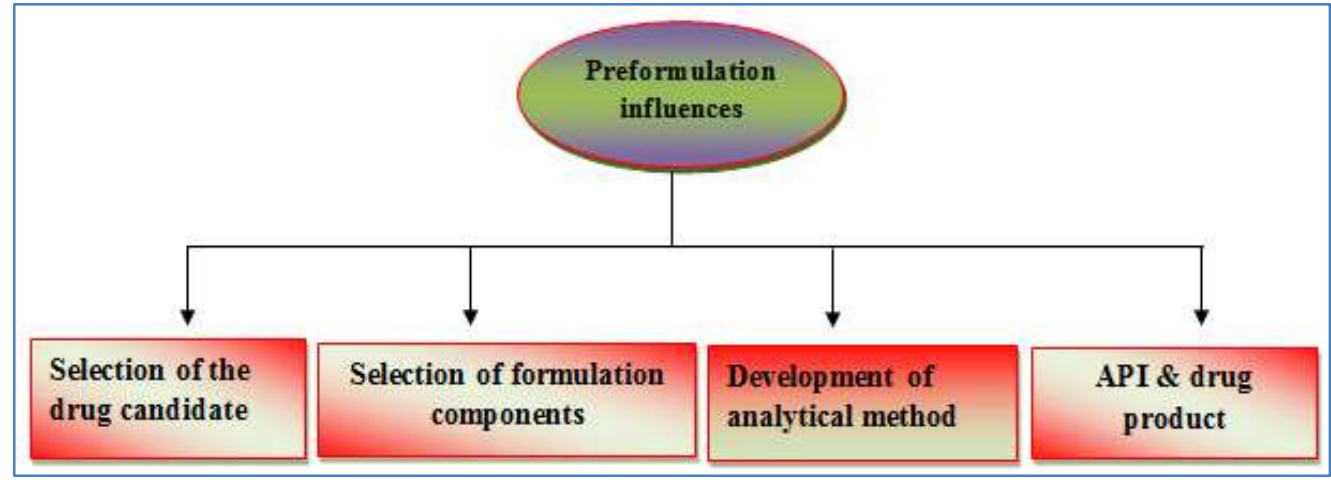

Econazole is a topical imidazole antifungal. floccosum. It also has in vitro activity but has not been Econazole inhibits fungal cytochrome P450 sterol c-14 alpha- clinically validated against T verrucosum, C guillermondii, C demethylation. This action blocks the conversion of lanosterol parapsilosis, and $\mathrm{C}$ tropicalis. Econazole is approved by the to ergosterol, an integral part of fungal membranes. It is active FDA for the treatment of tinea pedis, tinea cruris, tinea against Candida albicans, Malassezia furfur, Microsporum corporis, tinea versicolor, and cutaneous candidiasis [4]. species, Trichophyton species, and Epidermophyton 


\begin{tabular}{|l|l|}
\hline \multicolumn{2}{|c|}{ Drug (Econazole) description [5-7] } \\
\hline IUPAC Name & $1-[2-[(4-$ chlorophenyl)methoxy]-2-(2,4-dichlorophenyl)ethyl]imidazole \\
\hline Structure & \multicolumn{2}{|c|}{$\mathrm{C}_{18} \mathrm{H}_{15} \mathrm{Cl}_{3} \mathrm{~N}_{2} \mathrm{O}$} \\
\hline Molecular formula $381.68 \mathrm{~g} / \mathrm{mol}$ \\
\hline Molecular Weight & Solid, white \& odorless \\
\hline Nature & Freely sparingly soluble in ethanol, methanol, and water and practically insoluble in water. \\
\hline Solubility & Antifungal \\
\hline Therapeutic category
\end{tabular}

In the present works a challenge was made to study preformulation parameters of Econazole which helps to produce information useful in developing stable and Bioavailable dosage forms.

\section{MATERIAL AND METHODOLOGY}

Procurement of Drug: Econazole was obtained as gift sample from Qualikems laboratory reagent, New Delhi.

\section{Organoleptic properties}

Organoleptic properties of the drug sample were studied by visual inspection.

\section{Preformulation studies [8-11] \\ Identification of Drug \\ Melting Point Determination}

To determine the M.P. of drug powder, it was filled in a capillary tube with one end open and the other end closed and then the capillary was placed in a digital melting point apparatus.

\section{Solubility}

The drug was found to be freely soluble in water and in methanol, very slightly soluble in acetone, which matches the existing reference.

\section{Loss on drying}

The average LOD (\%w/w) and \% LOD were determined.

\section{Partition coefficient}

About 50mg of drug was dissolved in $50 \mathrm{ml}$ of distilled water and n-octanol separately and both the solution was mixed together by using wrist watch shaker for $30 \mathrm{~min}$. Then the solution was kept in a separating funnel until two phases separated. The aqueous phase was then filtered through the filter paper and was diluted 100 times. The absorbance of both the solutions was taken at $234 \mathrm{~nm}$ by using UV spectrophotometer. The concentration of drug was determined with the help of standard curve and partition coefficient was determined by following formula:

\section{Analytical Method}

UV Spectroscopy of drug performed on UV visible spectrophotometer at the UV -spectrophometer (Model: UV - 1700 Shimadzu) for performing this analysis serial dilution of different concentration of Econazole $\quad(10 \mu \mathrm{g} / \mathrm{ml}, \quad 15 \mu \mathrm{g} / \mathrm{ml}, 20$ $\mu \mathrm{g} / \mathrm{ml}$,and $25,30,35 \mu \mathrm{g} / \mathrm{ml}$ ) were prepared. Then observed absorbance of different concentrations of dilution and taken U.V. spectra at $267 \mathrm{~nm}$ of Econazole then plotted calibration graph of the Econazole.

\section{FTIR spectroscopy studies}

FTIR (ATR Bruker, Germany) was used. The IR spectrum was obtained by scanning it in the range 4000-500nm and compared with the reference pharmacopoeia (IP-2014).

Table-1: Preformulation Characteristics

\begin{tabular}{|l|l|l|}
\hline S.No. & Characteristics & Results \\
\hline 1. & Appearance & White, bitter, Solid \\
\hline 2. & Melting Point & Melting Point was found to be $163-165^{\circ} \mathrm{C}$. \\
\hline 3. & Partition coefficient & 4.78 \\
\hline
\end{tabular}

Table 2: Solubility data of the drug in different solvents/ buffers

\begin{tabular}{|l|l|l|}
\hline S.No. & Solvents & Econazole solubility \\
\hline 1 & Water & Slightly soluble \\
\hline 2 & $0.1 \mathrm{~N} \mathrm{NaOH}$ & Soluble \\
\hline 3 & Acetone & Soluble \\
\hline 4 & Ethanol & Slightly soluble \\
\hline 5 & Benzene & Soluble \\
\hline 6 & Chloroform & Sparingly soluble \\
\hline
\end{tabular}


Table 3: Percent loss on drying of Econazole

\begin{tabular}{|c|c|c|c|c|c|}
\hline S. No. & $\begin{array}{l}\text { wt. of before } \\
\text { drying(gm) }\end{array}$ & $\begin{array}{l}\text { wt. of after } \\
\text { drying(gm) }\end{array}$ & $\operatorname{LOD}(\% \mathrm{w} / \mathrm{w})$ & $\begin{array}{l}\text { Average } \\
\text { LOD }(\% \text { w/w })\end{array}$ & $\begin{array}{l}\text { Limit of } \\
\operatorname{LOD}(\% w / w)\end{array}$ \\
\hline 1 & 1 & 0.9986 & 0.11 & \multirow{3}{*}{0.14} & \multirow{3}{*}{$0.1-0.4$} \\
\hline 2 & 1 & 0.9986 & 0.13 & & \\
\hline 3 & 1 & 0.9985 & 0.14 & & \\
\hline
\end{tabular}

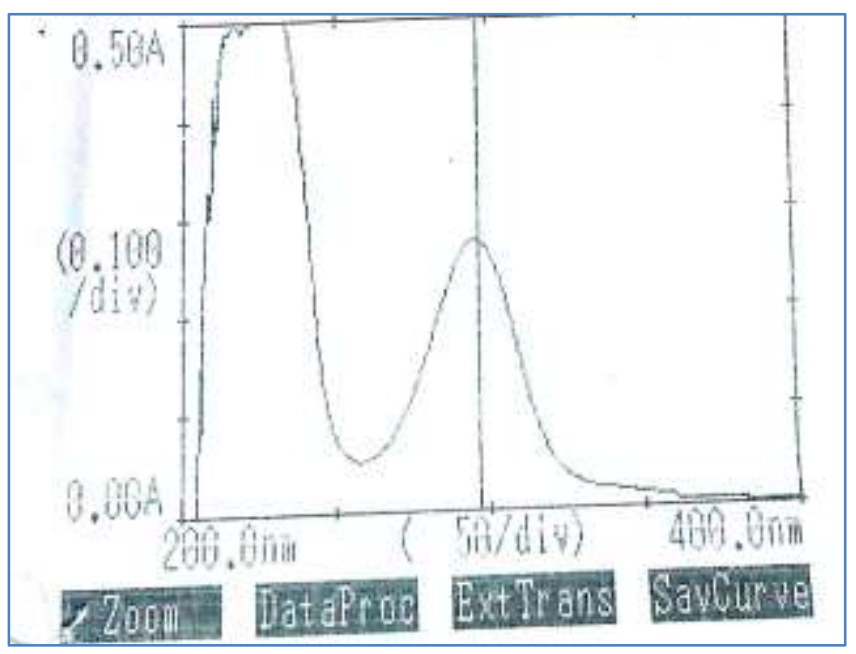

Fig-1: UV Spectra of drug of econazole

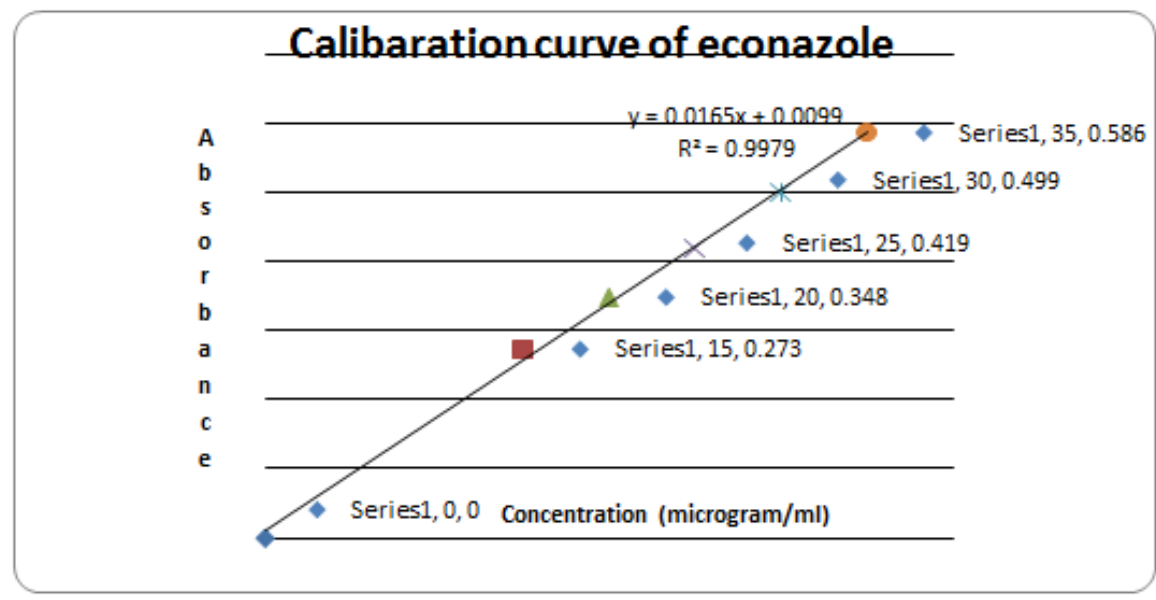

Fig-2: Graph showing caliberation curve of econazole

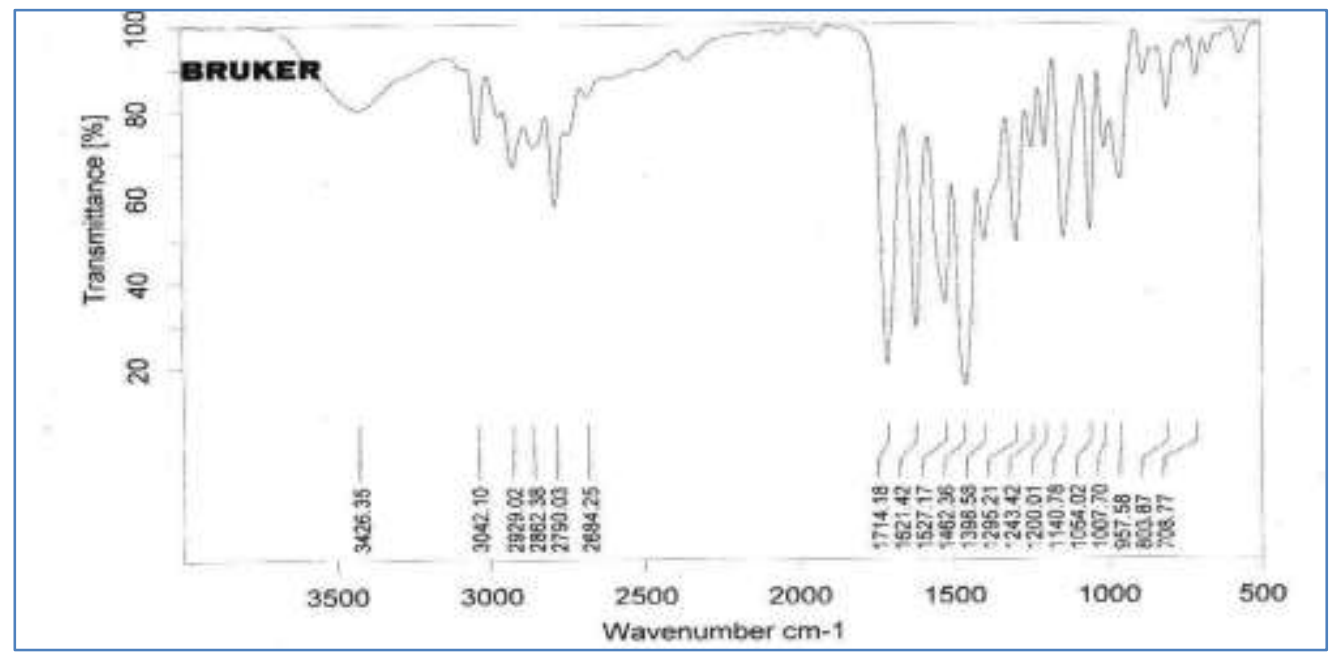

Fig-3: IR spectra of Econazole (sample) 
Table-4: Interpretation of IR spectrums

\begin{tabular}{|l|l|}
\hline Obtained peak values $\left(\mathbf{c m}^{-1}\right)$ & Functional group \\
\hline 3427 & N-H stretch \\
\hline 3109 & Aromatic C-H stretch \\
\hline 1585 & $\mathrm{NO}_{2}$ stretch \\
\hline 1547 & $\mathrm{C}=\mathrm{C}$ \\
\hline 3109 & $\mathrm{C}-\mathrm{N}$ stretch \\
\hline 638 & $\mathrm{C}-\mathrm{Cl}$ stretch \\
\hline
\end{tabular}

\section{RESULTS AND DISCUSSION}

The in broad purpose of the present work was to examine preformulation studies of Econazole is to generate information constructive in developing stable and Bioavailable dosage forms. Preformulation studies of drug were undertaken concerning melting point, solubility analysis, UV-spectrophotometric analysis and FTIR analysis to identify and evaluation of purity of drug. Various Preformulation Characteristics were tabulated in table 1 . The partition coefficient of rutin was found 4.78 , which confirms the lipophilicity of the drug. The drug was found to be freely soluble in water and in methanol, very slightly soluble in acetone, which matches the existing reference. From the result reported in the table 3 revealed that the loss of drying of the drug is within range 0.1-0.4. The analytical method for determination of drug was UV spectroscopy. The absorption spectral analysis showed the $\lambda_{\max }$ of Econazole at $267 \mathrm{~nm}$ (Fig.1-2). The FTIR spectrum, there was no variation in the Econazole peaks from the standard spectrum of IP 2014(fig 4). The result of interpretation of IR spectra was tabulated in table 4 . Preformulation studies revealed the purity of the drug. UV-spectrophotometric analysis of drug in distilled water $\left(y=0.156 x+0.0099, R^{2}=0.9979\right.$ revealed the suitability of the standard curve for further calculation.

\section{CONCLUSION}

The preformulation tread is a fundamental fraction in establishing the properties of drug that will allow appropriate hazard assessment for development. Frequently it begins all through the lead optimization phase, continues through predomination, and on into the early on phases of development. Consequently, it is compulsory that preformulation should be performed as carefully as possible to facilitate coherent decisions to be made. The preformulation study of Econazole is to make information useful in developing stable and Bioavailable dosage forms.

\section{REFERENCE}

1. Desu PK, Vaishnavi G, Divya K, Lakshmi U. An overview on preformulation studies. Indo american journal of pharmaceutical sciences. 2015 Oct 1;2(10):1399-407.

2. Karuppusamy C, Venkatesan P. Preformulation Parameters Characterization to Design, Development and Formulation of Miglitol Loaded Nanoparticles. Journal of Pharmaceutical Sciences and Research. 2017 Mar 1;9(3):326.

3. Kumar A, Kumar A, Malik JK. Preformulation studies of Drotaverine $\mathrm{HCl}$ : An integral part of formulation design. European Journal of Biomedical and Pharmaceutical Sciences. 2019;6(13):304-7.

4. Baloglu E, Karavana SY, Senyigit ZA, HilmiogluPolat S, Metin DY, Zekioglu O, Guneri T, Jones DS. In- situ gel formulations of econazole nitrate: preparation and in- vitro and in- vivo evaluation. Journal of Pharmacy and Pharmacology. 2011 Oct;63(10):1274-82.

5. Verma P, Pathak K. Nanosized ethanolic vesicles loaded with econazole nitrate for the treatment of deep fungal infections through topical gel formulation. Nanomedicine: Nanotechnology, Biology and Medicine. 2012 May 1;8(4):489-96.

6. Evelyn D, Wooi CC, Kumar JR, Muralidharan S, Dhanaraj SA. Development and evaluation of microemulsion based gel (MBGs) containing econazole nitrate for nail fungal infection. Journal of Pharmacy Research. 2012 Apr;5(4):2385-90.

7. Ambrogi V, Perioli L, Pagano C, Marmottini F, Moretti M, Mizzi F, Rossi C. Econazole nitrateloaded MCM-41 for an antifungal topical powder formulation. Journal of pharmaceutical sciences. 2010 Nov 1;99(11):4738-45.

8. Mehta RM. Processing of tablets, Pharmaceutics-1. Delhi: Vallabh prakashan. 2002:238-67.

9. Himesh Soni \& A.K. Singhai. Formulation and Development of Hydrogel Based System for Effective Delivery of Rutin. IJAP;5(1),(2013),5-13.

10. Himesh Soni. Preformulation Studies of Tramadol $\mathrm{HCl}$ : Vital Part of Formulation Design. EJBPS. 2020, 7(1): 369-373.

11. Vijaya C, Raghavan. A practical handbook of physical pharmaceutics 1 edition' April; 1995, 4157. 